\title{
Interaction between Crofer 22 APU Current Collector and LSCF Cathode Contacting Layer under Cell Operation
}

\author{
R. Spotorno ${ }^{\mathrm{a}}$, P. Piccardo ${ }^{\mathrm{a}}$, F. Perrozzi ${ }^{\mathrm{b}}$ \\ ${ }^{a}$ Department of Chemistry and Industrial Chemistry, University of Genoa, Genoa, Italy \\ ${ }^{\mathrm{b}}$ Institute for Energetics and Interphases, National Council of Researches, Genoa, Italy
}

In this work the oxidation of Crofer 22 APU and its interaction with $\mathrm{La}_{0.6} \mathrm{Sr}_{0.4} \mathrm{Co}_{0.2} \mathrm{Fe}_{0.8} \mathrm{O}_{3}$ (LSCF) applied as contacting layer have been investigated in air at $750^{\circ} \mathrm{C}$ under a current load of 0.5 $\mathrm{Acm}^{-2}$ with the aim to reproduce as close as possible the interconnect interface in real operating conditions. The effects of such interaction and of the pre-oxidation treatment have been studied by means of ASR measurement and post-experiment characterizations. The behavior of such samples has been compared with the results on a working Crofer 22 APU bipolar plate tested as cathode current collector of an anode-supported cell reproducing the stack cathode compartment conditions.

\section{Introduction}

The metal interconnect oxidation and interactions with the cell are issues limiting the performances and the durability of the SOFC stacks. Despite the application of additional surface treatments or protective coatings such issues are still affecting the system reliability because of hardly avoidable interactions since the operating conditions to which such material are exposed. Beside the high temperatures and oxygen partial pressures one should also consider the presence of a current load, which acts locally changing the working conditions, and the kinetic aspect of the oxidation processes.

In this study Crofer 22 APU has been tested "as received" without any additional treatment in comparison with the pre-oxidized one. Samples have been coated with LSCF applied as cathode contacting layer in order to reproduce the same interface present at the cathode compartment in a SOFC stack. Investigations have been carried out measuring the evolution of the electrical resistance of the sample and by post-experiment characterization aiming to understand the interaction between the involved materials. A comparison with a bipolar plate tested as cathode current collector of an anode-supported cell allowed to confirm the results obtained on the reproduced interfaces.

Crofer 22 APU (ThyssenKrupp VD) is a ferritic stainless steel especially developed for application in solid oxide fuel cells and recognized as standard material for interconnects. For these reasons it has been chosen for the research discussed in this paper.

Several solutions can be followed in order to improve the characteristics of the steel exposed at operating conditions. The pre-oxidation at a temperature higher than the working one is a cheap tentative of protection frequently used for high temperature applications since the beneficial effects of the formation of a stable $\mathrm{Cr}$, $\mathrm{Mn}$ spinel on the steel surface. It can reduce the cathode poisoning rate since the formation of $\mathrm{Cr}^{\mathrm{VI}}$ volatile compounds from the spinels is from 1 to 2 orders of magnitude lower than from the 
chromia (1-4). Most of the published researches deals with the chromium poisoning directly related to the volatile compounds while the solid state diffusion occurring at cathode-interconnect interface is rarely treated. This interface plays the fundamental role to transfer the electrons from the interconnect to the cathode for the reduction of the oxygen. A specific contact paste can help in this purpose and LSCF can be a promising contact paste thanks to its electronic conductivity (at high temperature) and to its chemical similarity with the cathode (typically made of the same materials in the nowadays state of the art cells). LSCF is as well considered a chromium getter which could be an important issue to absorb the $\mathrm{Cr}$ species released by the interconnect before they enter in contact with the cathode. This layer is not meant to participate to the catalysis of the reduction of oxygen.

\section{Materials and methods}

Crofer 22 APU sheets $0.5 \mathrm{~mm}$ thick have been cut using waterjet in $25 \mathrm{~mm}$ diameter discs suitable for the electrical tests. Samples have been tested "as received" or with an additional pre-oxidation treatment of 5 hours at $900^{\circ} \mathrm{C}$. $\mathrm{La}_{0.6} \mathrm{Sr}_{0.4} \mathrm{Co}_{0.2} \mathrm{Fe}_{0.8} \mathrm{O}_{4}$ ( $\mathrm{LSCF}$, Fuelcellmaterials, USA) has been applied on both faces of the discs by colloidal spraying obtaining homogeneous layers which reproduce the interface steel-contacting layer or steel-electrode. Discs have been contacted with platinum meshes and four-probe DC resistance measurements were then performed in static air for about 100 hours at $750^{\circ} \mathrm{C}$. Measures were performed with a potentiostat-galvanostat (Solartron Schlumberger SI 1286 Electrochemical Interface) applying a DC current load of $500 \mathrm{mAcm}^{-2}$.

After each degradation test, samples have been mounted in epoxy resin and cut to expose their cross-section. They were subsequently metallographically polished with a diamond suspension up to $250 \mathrm{~nm}$ grain size. The samples where then ultrasonically washed in absolute ethanol and dried. Lastly, they were gold plated (5 nm thick Au layer) for further observations by SEM equipped with SE/BSE detectors and EDX spectroscopy sensitive to light elements. The post-experiment results have been compared with those related to a Crofer 22 APU bipolar plate stamped from a sheet of the same batch used in this study and tested in contact with the cathode of an anode-supported cell. Between the bipolar plate and the electrode the LSCF contacting paste has been applied with the aim to improve the cell performances increasing the contact area between the two elements. The cell testing has been carried out for 100 hours at the temperature of $750^{\circ} \mathrm{C}$ using 1 Nlpm air flow at the cathode side, in the bipolar plate channels.

\section{Results}

The application of a current load to the samples under investigation offered the possibility to measure their resistance and calculate the ASR for a performance comparison. ASR of Crofer 22 APU without any contact layer highlights the excellent electrical behavior under oxidation conditions of such material (figure 1). It showed an increase of the resistance in the first testing hours reaching stabilization on the ASR after 10 hours. During the rest of the experiment it has been measured a stable electrical resistance which slightly decreases after 60 hours of the test until the end. Problems arose when the metal was in contact with the cathode contacting material, LSCF, which brought to a considerable increase of the ASR. In the sample constituted by as-received steel with an applied contacting layer the resistance has grown assuming, after 20 hours, a 
linear increase meanwhile in the pre-oxidized steel with LSCF a significant mitigation of the resistance increase is noticeable limiting its values since the beginning of the test and reducing the slope of the linear growth in comparison with the previous sample.

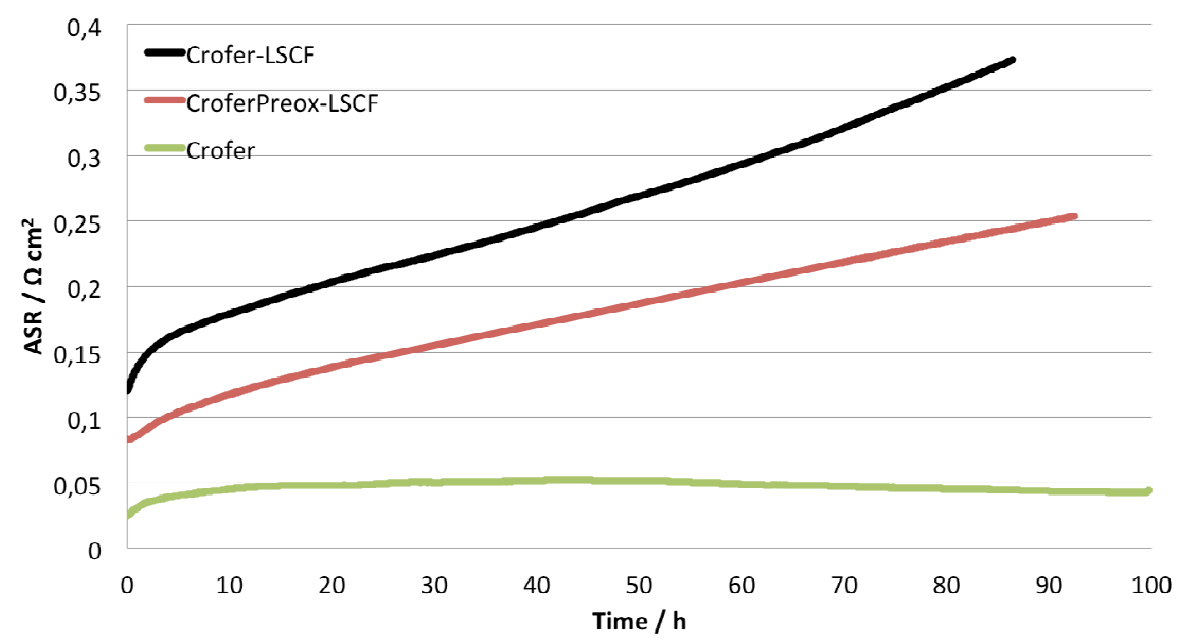

Figure 1. ASR at $750^{\circ} \mathrm{C}$ for 100 hours of Crofer 22 APU (green curve) and LSCF coated Crofer 22 APU, as-received (black curve) and pre-oxidized (red curve).

From the post-experiment characterization the Crofer 22 APU sample without LSCF exhibited a dense oxide layer on its surface with a chromium distribution between 20 at. $\%$ and 30 at. $\%$ along the cross-section (figure 2). The iron amount decreases in the first $500 \mathrm{~nm}$ of the scale to values below 10 at.\% meanwhile the Mn reaches a maximum value of 15 at.\% in the oxide layer.
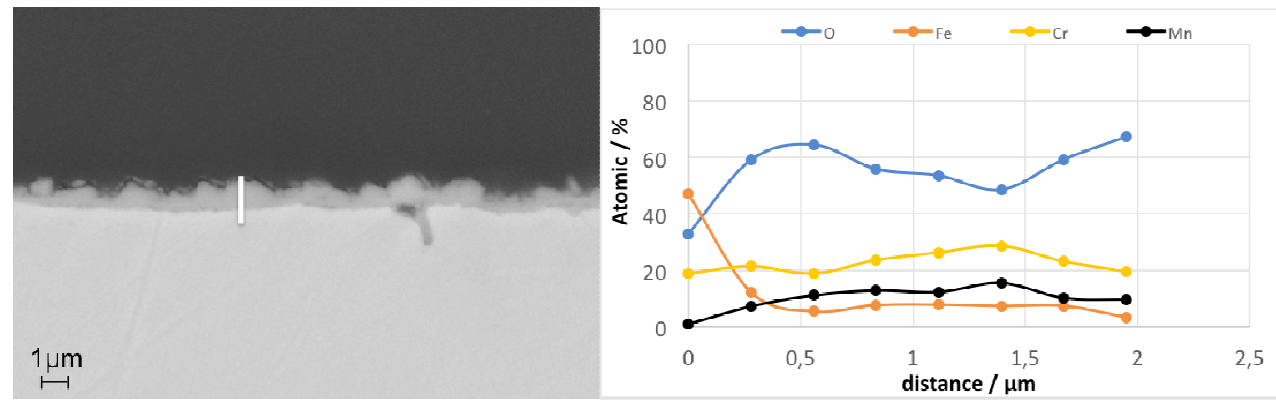

Figure 2. SEM-BSE image in cross-section (left) and EDX analyses results along the white line (right) of Crofer $22 \mathrm{APU}$ aged at $750^{\circ} \mathrm{C}$ with $0.5 \mathrm{Acm}^{-2}$ applied current load.

In the sample coated with LSCF the chromium amount is suddenly decreasing after the oxide-contacting material interface (figure 3, table I). This element reacts with the LSCF forming dense phases scattered on the whole volume of the layer and constituted by strontium chromates. They most probably surround the original crystals of the doped ferrite. The estimated porosity of the contacting layer was of $31 \%$.

The pre-oxidation treatment favored the formation of a spinel layer with geometric crystals covering a thin chromia-based scale (figure 4), as it is common for FSS oxidized at high temperature. 

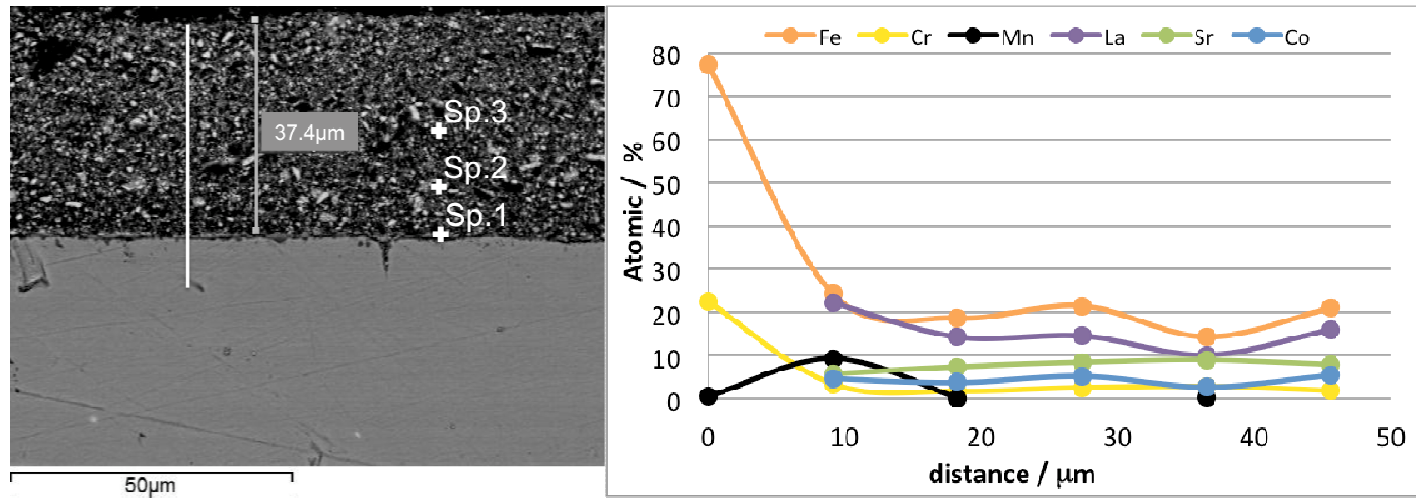

Figure 3. SEM-BSE image in cross-section (left) and EDX analyses results along the white line (right) of Crofer 22 APU-LSCF cathode side aged at $750^{\circ} \mathrm{C}$ with $0.5 \mathrm{Acm}^{-2}$ applied current load. Additional EDX point analyses results are listed in table I

TABLE I. EDX analyses results of measure points indicated in figure 3

\begin{tabular}{cccccccc}
\hline Sp. & O / at.\% & Cr / at.\% & Mn / at.\% & Fe / at.\% & Co / at.\% & Sr / at.\% & La / at.\% \\
\hline 1 & 47 & 26.7 & 2.6 & 23 & 0.4 & 0.1 & 0.4 \\
2 & 50 & 3.54 & - & 20 & 4.8 & 8.5 & 14 \\
3 & 46 & 1.82 & 0.1 & 23 & 6.4 & 7.6 & 16 \\
\hline
\end{tabular}
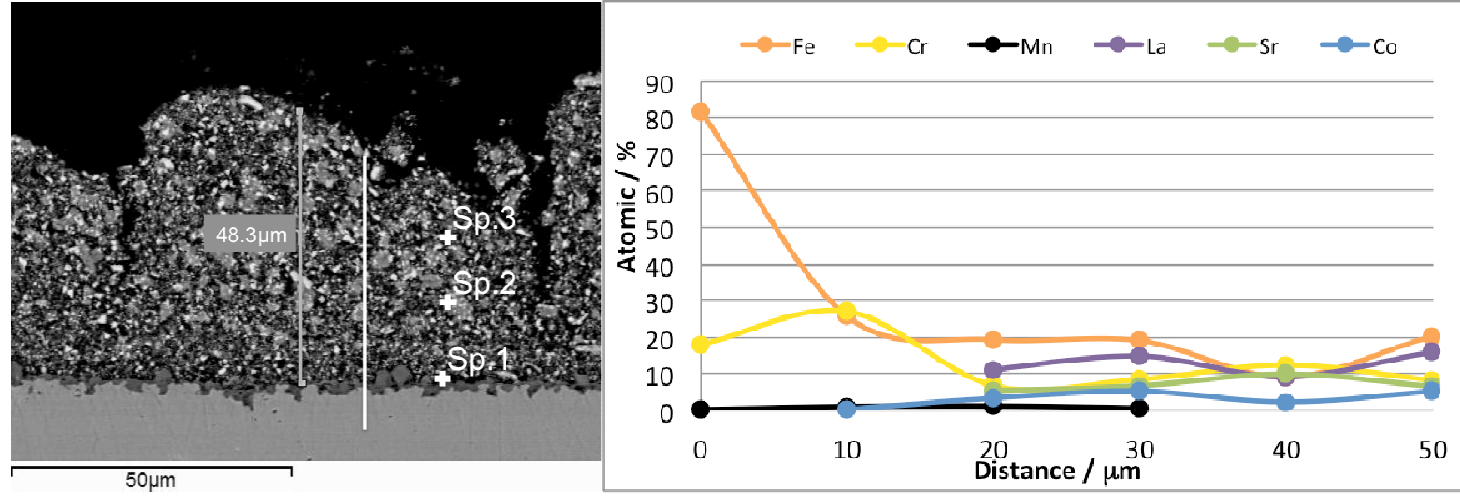

Figure 4. SEM-BSE image in cross-section (left) and EDX analyses results along the white line (right) of Crofer 22 APU (pre-oxidized)-LSCF cathode side aged at $750^{\circ} \mathrm{C}$ with $0.5 \mathrm{Acm}^{-2}$ applied current load. Additional EDX point analyses results are listed in table II

TABLE II. EDX analyses results of measure points indicated in figure 4

\begin{tabular}{cccccccc}
\hline Sp. & O / at. \% & Cr / at.\% & Mn / at.\% & Fe / at.\% & Co / at.\% & Sr / at. \% & La / at.\% \\
\hline 1 & 64.6 & 17.8 & 5.5 & 4.2 & 6.1 & 0.7 & 1.2 \\
2 & 53.9 & 7.9 & 0.7 & 14.1 & 3.5 & 8.3 & 11.6 \\
3 & 48.6 & 8.6 & - & 18.0 & 4.6 & 6.5 & 13.7 \\
\hline
\end{tabular}

Compared to the previous sample the chromium diffuses deeper into the LSCF layer. It forms well visible dense agglomerated homogeneously dispersed and keeping the 
amount of this element rather high until the edge is reached. The highest $\mathrm{Cr}$ and $\mathrm{Mn}$ amounts have been found in the oxide scale at the interface between the steel and the LSCF. In this case manganese concentrates less in the oxide layer and shows a limited diffusion toward the contacting material. Detailed analyses on various phases show that the steel oxide scale is rich in chromium and iron with a limited amount of manganese. Some Co, La and $\mathrm{Sr}$ are diffusing as well (figure 4, table II). The stronger formation of dense Cr- and Sr-rich phases in the LSCF reduces its porosity to $15 \%$.

The steel tested as current collector for an anode-supported cell exhibited a similar oxidation behavior and interaction with the contacting layer compared to the previously described samples. The cross-sections in figure 5 and figure 6 show a bipolar plate rib, where the steel is in contact with the LSCF layer. A part of this layer remained attached to the steel after the cell was removed. From the EDX map the presence of chromium migrated toward the contacting material can be observed (figure 5). EDX spot analyses confirmed such results (figure 6, table III) quantifying the chromium amount close to the steel at 4.55 at.\%. The oxide formed over the steel surface is characterized by the presence of a white (in BSE) iron-rich area (37 at.\%) in the middle of the scale. The remaining part is constituted by two grey similar phases, one is dense and located at the interface with the steel, the other one is thicker and characterized by more defects and irregularities in its structure. The inner layer contains a high amount of oxygen (50.5 at.\%) and chromium (23.7 at.\%) meanwhile the external one is characterized by the presence of significant amounts of strontium (13.7 at.\%), lanthanum (1.1 at.\%) and cobalt $(0.82$ at.\%). A limited amount of titanium $(<0.3$ at.\%) was also found in the oxide scale.

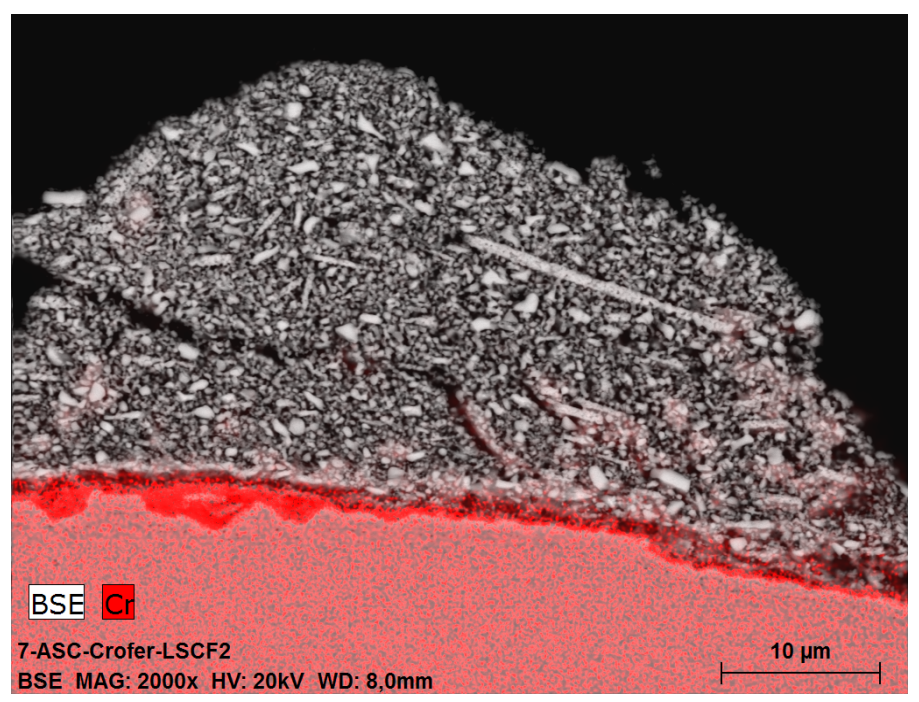

Figure 5. SEM-BSE of an interconnect rib in surface with superimposed EDX map of chromium 


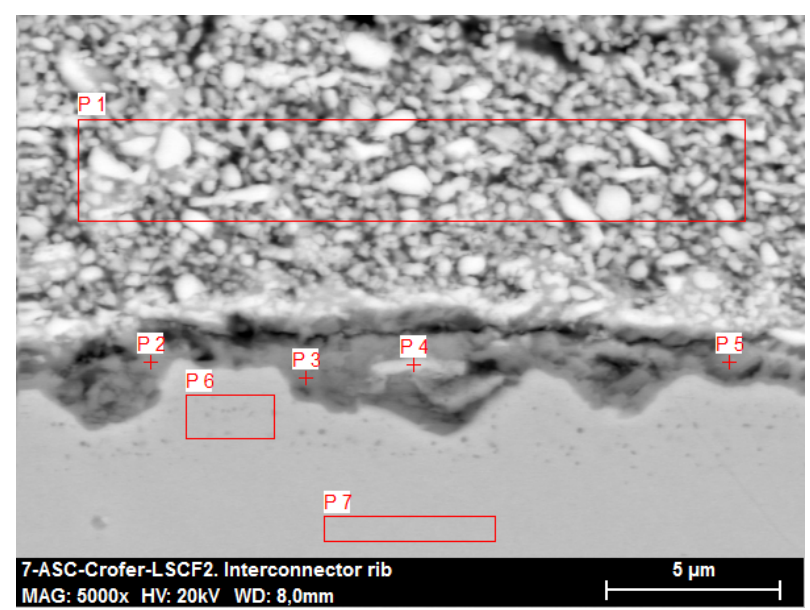

Figure 6. SEM-BSE image of an interconnect cross-section in correspondence of a rib

TABLE III. EDX analyses results of measure points and areas indicated in figure 6

\begin{tabular}{llccccccccccc}
\hline Sp. & $\begin{array}{l}\text { O / } \\
\text { at.\% }\end{array}$ & $\begin{array}{c}\text { Mg / } \\
\text { at.\% }\end{array}$ & $\begin{array}{c}\text { Al / } \\
\text { at.\% }\end{array}$ & $\begin{array}{l}\text { S / } \\
\text { at.\% }\end{array}$ & $\begin{array}{c}\text { Ca / } \\
\text { at.\% }\end{array}$ & $\begin{array}{c}\text { Ti / } \\
\text { at.\% }\end{array}$ & $\begin{array}{c}\text { Cr / } \\
\text { at.\% }\end{array}$ & $\begin{array}{c}\text { Mn / } \\
\text { at.\% }\end{array}$ & $\begin{array}{c}\text { Fe / } \\
\text { at.\% }\end{array}$ & $\begin{array}{c}\text { Co / } \\
\text { at.\% }\end{array}$ & $\begin{array}{c}\text { Sr / } \\
\text { at.\% }\end{array}$ & $\begin{array}{c}\text { La / } \\
\text { at.\% }\end{array}$ \\
\hline P1 & 54.22 & - & - & - & - & - & 4.55 & - & 18.02 & 4.27 & 6.82 & 12.13 \\
P2 & 60.46 & - & - & - & 0.30 & 0.23 & 23.70 & 2.33 & 9.78 & - & 2.70 & 0.50 \\
P3 & 57.13 & - & 0.10 & 0.10 & 0.39 & 0.29 & 25.27 & 2.95 & 11.79 & 1.04 & 0.96 & - \\
P4 & 37.05 & 0.25 & - & 0.24 & 0.67 & 0.25 & 22.56 & - & 36.98 & - & 1.46 & 0.53 \\
P5 & 55.59 & - & - & - & 0.33 & - & 20.08 & 2.19 & 6.21 & 0.82 & 13.70 & 1.09 \\
P6 & 34.96 & - & - & - & 0.24 & - & 14.19 & - & 36.71 & 2.61 & 4.94 & 6.35 \\
P7 & 35.38 & - & - & - & 0.25 & - & 14.15 & - & 36.56 & 2.44 & 5.05 & 6.17 \\
\hline
\end{tabular}

\section{Discussion}

The electrical measurements have shown that the Crofer 22 APU maintains a stable ASR during the first $100 \mathrm{~h}$, which tend to decrease during the aging test. Such effect can be related to changes in the oxide scale, which could refer to the composition or the microstructural aspect and to the limited thickness growth of the oxide scale. It is known (5) that on the top of the scale is common to have the formation of a $(\mathrm{Cr}, \mathrm{Mn})_{3} \mathrm{O}_{4}$ spinel which has an higher conductivity than the chromia. Alternatively, microstructural changes can be due to the oxidation reaction of chromia to form volatile $\mathrm{Cr}^{\mathrm{VI}}$-based compounds, which could cause a thickness reduction and densification of the oxide $(1,2$, $6)$.

The higher electrical resistance values measured on samples coated with LSCF are due to the lower contacting material conductivity compared to the metal substrate. The testing conditions led to a sintering of such layers (figures 3 and 4), however the ASR increase of samples is revealing the interaction issues between those materials significantly changing their electrical behavior in time. LSCF is known to be a good chromium getter $(7,8)$ because of its tendency to absorb and contain a large amount of $\mathrm{Cr}$, which is fixed on the material surface forming secondary phases as shown by the EDX analyses. The presence of low-conducting Cr-based phases can be then the cause of the decreased overall conductivity of the sample.

The pre-oxidation applied to the Crofer 22 APU resulted in a limited protection at the cathode side. About the observed scale composition we can state that the high amount of iron is mainly due to the Fe from the LSCF and this might result in a reduced 
participation of Mn to the spinel formation. Alternatively, it is possible that higher $\mathrm{Mn}$ concentration was present in the original scale formed after the pre-oxidation treatment, which has diffused into the LSCF being substituted by iron during the aging test.

The amount of chromium diffusing into the LSCF was higher for the pre-oxidized Crofer 22 APU when compared with the "as received" sample meaning that the applied thermal treatment resulted not effectively stopping the $\mathrm{Cr}$ diffusion into the LSCF. This behavior can be explained considering the higher available chromium amount in the oxide scale, which was accumulated during the pre-treatment. Despite the lower volatility due to the presence of manganese in the oxide, it can migrate by solid-state diffusion toward the contacting layer. The higher chromium amount can be responsible of the differences in the contacting layer densification. The higher density measured in the preoxidized sample could have mitigated the ASR increase during the 100 hours of test.

The bipolar plate aged in contact with the cathode material of the anode-supported cell allowed to confirm the post-experiment results of the previously described samples. The scale formed over the steel surface was mainly made of $\mathrm{Cr}_{2-\mathrm{x}} \mathrm{Fe}_{\mathrm{x}} \mathrm{O}_{3}$ and $(\mathrm{Cr}, \mathrm{Mn})_{3} \mathrm{O}_{4}$, in agreement with other studies (9-13) and comparable with the "as-received" Crofer 22 APU under the compositional point of view as expected since similar experimental conditions have been applied in term of gas flow, temperature and current load. The EDX map showed the tendency of inhomogeneous chromium distribution along the contacting material with the formation of agglomerated phases. Such behavior is well comparable between the two kinds of samples underlying the twofold chromium migration mode by evaporation and solid state diffusion. In the relatively short ageing time of this study the solid state diffusion resulted more effective than the classical chromium poisoning process by oxidation evaporation and reduction of chromium rich species. This was especially confirmed by the EDX analyses performed on the pre-oxidized sample. This research, besides confirming the need of protective coatings in order to avoid the issues caused by chromium diffusion into the cathode, highlights the need to investigate the solid state diffusion between the coating and the cathode as an important parameter in order to select the most effective materials for reliable and durable SOFC stacks.

\section{Conclusions}

In this work the oxidation of Crofer 22 APU and its interaction with the cathode contacting layer have been studied reproducing such interface and the cell operating conditions of the cathode side. The detrimental effect of the interaction between the two materials at the interface has been measured from the electrical point of view showing a significant increase of the resistance. The comparison with a bipolar plate tested at the cathode side of an operating anode-supported cell confirmed the effectiveness of the reproduced steel-contacting material interface by post-experiment characterization. An additional test on pre-oxidized Crofer 22 APU showed the beneficial effect of this thermal treatment to limit the electrical resistance increase by forming a stable spinel oxide on the top of the scale. This mitigates the chromium evaporation but has a limited efficacy to stop the solid state diffusion of $\mathrm{Cr}$ and $\mathrm{Mn}$ into the cathode contacting layer. The solid state diffusion at this interface, representing the condition of the ribs in a real interconnect, is the main interaction between the cathode material and the metallic interconnect. Further studies on coatings shall take this result into account in order to determine the interdiffusion rate between the coating and the cathode of a real SOFC in a stack. 


\section{References}

1. G.R. Holcomb, D.E. Alman, Scripta Mater, 54, 1821 (2006)

2. G.R. Holcomb, Oxid. Met., 69, 163 (2008)

3. B. Hua, Y. Kong, W. Zhang, J. Pu, B. Chi, L. Jian, Journal of Power Sources, 196, 7627 (2011)

4. M. Stanislowski, J. Froitzheim, L. Niewolak, W.J. Quadakkers, K. Hilpert, T. Markus, L. Singheiser, Journal of Power Sources, 164, 578 (2007)

5. Z. Yang, J.S. Hardy, M.S. Walker, G. Xia, S.P. Simner, J.W. Stevenson, J.Electrochem. Soc., 151, A1825 (2004)

6. B. Pujilaksono, T. Jonsson, H. Heidari, M. Halvarsson, J.E. Svensson, L.G. Johansson, Oxid. Met., 75, 183 (2011)

7. T. Horita, D. H. Cho, F. Wang, M. Nishi, T. Shimonosono, H. Kishimoto, K. Yamaji, M. E. Brito, and H. Yokokawa, ECS Transactions, 51 (1), 69-77 (2013)

8. Grace Y. Lau, Michael C. Tucker, Craig P. Jacobson, Steven J. Visco, Stacy H. Gleixner, Lutgard C. DeJonghe, Journal of Power Sources, 195, 7540 (2010)

9. T. Horita, H. Kishimoto, K. Yamaji, Y. Xiong, N. Sakai, M. E. Brito, H. Yokokawa, Journal of The Electrochemical Society, 153, A2007 (2006)

10. V. Miguel-Pérez, A. Martínez-Amesti, M. L. Nó, A. Larrañaga, M. I. Arriortua, Corrosion Science, 60, 38 (2012) $\square$

11. K. Kawamura, T. Nitobe, H. Kurokawa, M. Ueda, T. Maruyama, Journal of The Electrochemical Society, 159, B259 (2012)

12. M. Linder, T. Hocker, L. Holzer, K. A. Friedrich, B. Iwanschitz, A. Mai, J. A. Schuler, Journal of Power Sources, 243, 508 (2013) 508

13. P. Piccardo, S. Anelli , V. Bongiorno, R. Spotorno, L. Repetto , P. Girardon, International Journal of Hydrogen Energy, 40, 3726 (2015) 